\title{
Sialolithiasis of the submandibular salivary duct - A case report
}

\author{
Neeraj $^{1}$, Neha Jajodia' ${ }^{2, *}$, Banshi Lal Beniwal ${ }^{3}$, Vijay Maliwad $^{4}$, Vikas Berwal $^{5}$ \\ ${ }^{1}$ Senior Resident, Dept. of Dentistry, Govt. Medical College and Hospital, Chandigarh, ${ }^{2,3,5} \mathrm{MDS},{ }^{4}$ Post graduate Trainee, Pandit \\ Bhagwat Dayal Sharma Post Graduate Institute of Medical Sciences, Rohtak, Haryana, India
}

\section{*Corresponding Author:}

Email: drjajodianeha@gmail.com

\begin{abstract}
Sialoliths of the salivary gland and duct are the most common pathologies of the salivary gland. This report describes management of a case of sialolith of the submandibular salivary gland and emphasises the role of CBCT imaging in localisation of sialoliths.
\end{abstract}

Keywords: Sialolith, Submandibular duct, CBCT.

\section{Introduction}

Sialolithiasis is a commonly encountered condition, characterized by obstruction of a salivary gland or its excretory duct due to the formation of calcium deposits/ sialoliths. ${ }^{1}$ It is estimated that sialolithiasis affects 12 out of every 1000 patients in the adult population. ${ }^{2}$ It accounts for $30 \%$ of all salivary gland disorders and is the second most common condition after mumps. ${ }^{3}$ The disease has a higher incidence in males aged 30 to 60 years. $^{2}$ More than $80 \%$ sialoliths occur in the submandibular gland or its duct. ${ }^{4}$ Single calculi can sometimes grow to large sizes resulting in mechanical obstruction of the saliva. ${ }^{5}$

We report the management of a case of Sialolith in the Left submandibular duct diagnosed on a Cone beam Computed Tomography (CBCT).

\section{Case Report}

The patient, a 37-year-old male, reported to the maxillofacial clinic with complaint of a dull, intermittent, ache in the left submandibular region since 6-7 months. He reported that his discomfort aggravated greatly at meal times especially on consumption of sour food. Patient's medical history was unremarkable.

On examination, mild swelling was noted in the left submandibular area. (Fig. 1) A firm mass was palpable around half a centimeter in diameter, along the course of the left submandibular duct. The mass was slightly tender and bimanually palpable. Both the submandibular glands were non-tender. Salivary flow from the duct orifice was noted on massaging the glands on both sides but it was less from the left submandibular duct. The patient was afebrile, and his vital signs were normal. The rest of the findings of the physical examination were unremarkable. On the basis of the history and physical findings, a clinical diagnosis of left submandibular sialolithiasis was made.

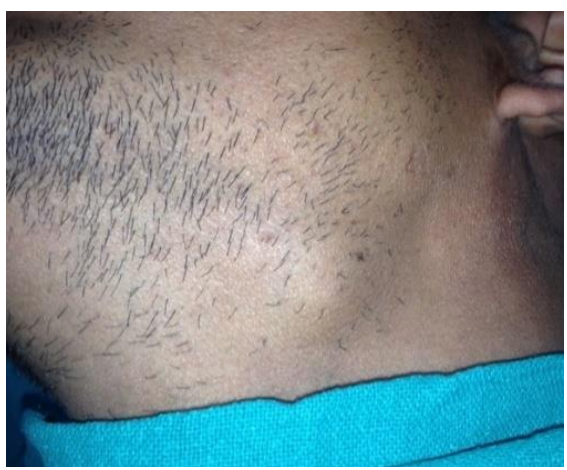

Fig. 1

For radiographic evaluation a Cone Bean Computed Tomography was done. It reported a $6.6 \mathrm{~mm}$ by $6 \mathrm{~mm}$ size calculi in the left submandibular duct obstructing the flow. (Fig. 2a, 2b)

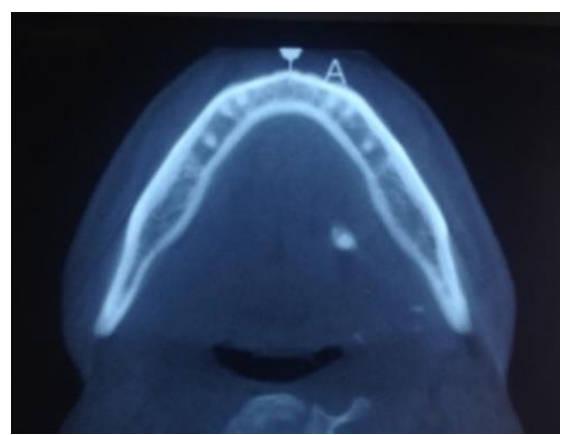

Fig. 2(a) 


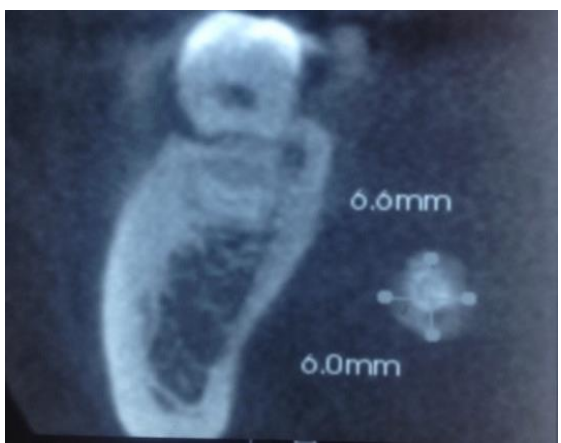

Fig. 2(b)

Patient was planned for surgical removal of the sialolith under local anaesthesia. An incision was made through the oral mucosa over the area where stone was palpable, lateral to but along the course of the left submandibular duct. (Fig. 3) The duct was carefully dissected to expose the large calculus. The calculus was separated from the soft tissue by blunt dissection and carefully removed from the submandibular duct. The wound was left to heal by secondary intention. It measured $6.5 \times 6 \mathrm{~mm}$ in greatest dimension and weighed $0.27 \mathrm{~g}$ Minute cracks were seen on the surface of this calculus (Fig. 4).

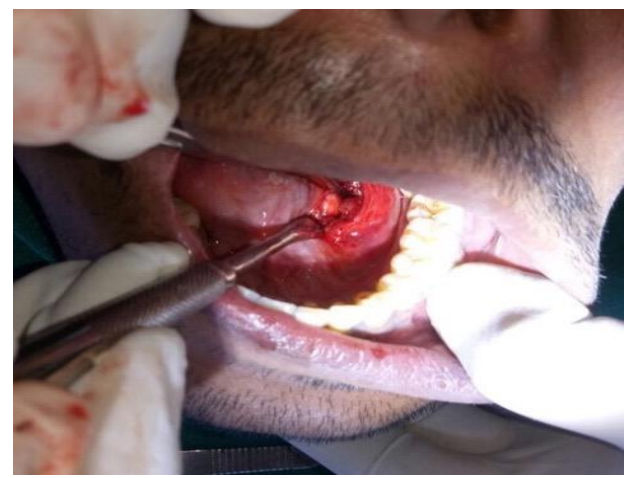

Fig. 3

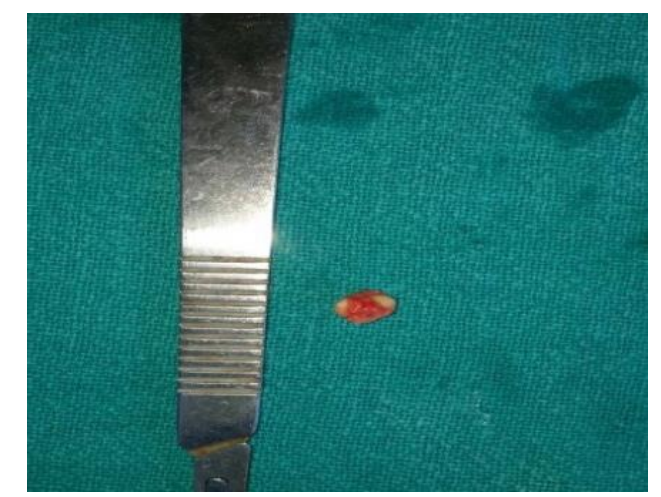

Fig. 4

\section{Discussion}

Sialolithiasis is caused by obstruction of a salivary gland or its excretory duct by a calculus. Sometimes, patients with sialoliths may be symptom free and an incidental discovery of the siololith may be made on jaw imaging. But mostly they are characterized by very classic symptoms like recurrent episodes of pain and swelling in the involved salivary gland. These symptoms are secondary to duct obstruction and aggravate at meal times when saliva production is maximum but its flow faces mechanical obstruction. Suppuration and sialadenitis of the involved gland can be a common sequelae. ${ }^{6}$

Our patient reported that he had intermittent, dull, aching pain and swelling in the left submandibular gland for 6 to 7 months more so at meal times and consumption of sour food items. As his symptoms were mild there may have been only a partial obstruction of the duct.

Salivary stagnation, increased alkalinity of the saliva, increased calcium content of the saliva, infection or inflammation of the salivary duct or gland, and physical trauma to the salivary duct or gland may predispose to calculus formation. The submandibular gland is the most susceptible of the three major salivary glands to sialolith formation. This is attributable to the saliva being more alkaline, with a greater concentration of calcium and phosphate. It also has a higher mucus content than the saliva of the parotid and sublingual glands. The submandibular duct has a longer course with a kink near the floor of the mouth and flows against gravity. ${ }^{7}$

Although the cause of salivary stone formation remains unclear, there are two main theories to explain the formation of salivary stones. The first theory postulates that inflammatory process in the local area may lead to calcification of a mucus plug. The second theory suggests that Salivary calculi may develop as a consequence of mineral salt deposition around a nidus of bacteria, mucus, or desquamated cells. ${ }^{8}$ Salivary stones are mainly calcareous concretions of inorganic material including hydroxyapatite, carbonate apatite, whitlockite, and brushite, with low amounts of organic material, such as collagen, lipids, glycoproteins, and carbohydrates. ${ }^{9}$

Although it is simple to diagnose this condition based only on signs and symptoms, imaging studies remain an essential component of management. Imaging for salivary calculi primarily include conventional radiographs, sialography, and ultrasonography. Conventional intraoral and panoramic imaging may at times not be able to detect/ dilineate these sialoliths if calcification is less and have limited usefulness. Sialography with dye injection is a useful aid to visualize the entire ductal system but is not indicated in infections or dye sensitivity and can sometimes complicate removal due to dislocation of the sialolith. ${ }^{10}$ High resolution, noncontrast computed tomography (CT) has been the modality of choice for salivary gland imaging. $11 \mathrm{In}$ recent times, the popularity of CBCT has been increasingly for maxillofacial diagnostic purposes. ${ }^{12}$ The CBCT scanner can collect volume data with a single rotation of 9-40 seconds. CBCT Sialography was first reported by Drage and Brown ${ }^{13}$ who concluded its 
superiority over conventional sialography. They also reported that $3 \mathrm{D}$ reconstruction could be viewed that would be useful for viewing areas of complex anatomy. $\mathrm{CBCT}$ also results in lower radiation exposure than a conventional CT.

In our case as well, we subjected the patient to a CBCT imaging and the sialolith was clearly visible on the imaging. The single calculi noted towards the farther end of the submandibular duct was larger in size and weight than usual for the duct. It measured $6.5 \times 6 \mathrm{~mm}$ and weighed $0.27 \mathrm{~g}$. Large sialoliths within the salivary glands are quite common, ${ }^{5,14,15}$ but they are comparatively rare in the salivary ducts. ${ }^{6,17}$

Different authors have reported the management of sialoliths presenting within the gland and duct structure. $^{18}$ Oral incision directly over the stone to dissect it from surrounding structures is a minimally invasive procedure when the sialoliths are noted in the distal part of the duct as in our case. ${ }^{6}$ We also accessed the sialolith from the intraoral route via a small incision. The patient was discharged following the procedure with a prescription of antibiotics and analgesics.

\section{Conclusion}

Sialoliths are a common clinical entity. This case emphasises on the clinical diagnosis based on symptoms, with a suggestion of subjecting patients to CBCT imaging for better localisation of the sialolith.

\section{References}

1. Torres-Lagares, D., et al., Parotid sialolithiasis in Stensen's duct. Med Oral Patol Oral Cir Bucal, 2006.11(1):p. E80-4.

2. lro H, Schneider HT, Födra C, et al. Shockwave lithotripsy of salivary duct stones. Lancet 1992;339:13336.

3. Andretta, M., et al., Current opinions in sialolithiasis diagnosis and treatment. Acta Otorhinolaryngol Ital, 2005. 25(3): p. 145-9.

4. Thoma KH. Thoma's oral pathology. St Louis: CV Mosby; 1970. p. 997-1002.

5. Ledesma-Montes C, Garces-Ortiz M, Salcido-Garcia JF, Hernandez-Flores F, Hernandez-Guerrero JC. Giant sialolith: Case report and review of the literature. J Oral Maxillofac Surg 2007;65:128-30.

6. 6.Soumithran D, Mathew D, Dev D, Mithilesh D, Fazmiya D. Parotid Sialolithiasis: A Case Report. IOSR Journal of Dental and Medical Sciences. 2016;15(07):96100.

7. Rice DH. Sialolithiasis. In: Paparella MM, Shumrick DA, Gluckman JL, et al, editors. Otolaryngology.

Philadelphia: WB Saunders; 1991. p. 2092-3.

8. Rice DH. Sialolithiasis. In: Paparella MM, Shumrick DA, Gluckman JL, et al, editors. Otolaryngology. Philadelphia: WB Saunders; 1991. p. 2092-3.

9. Carr SJ. Sialolith of unusual size and configuration. Oral Surg Oral Med Oral Pathol 1965;20:709-12.

10. Kraaij, S., et al., Systemic diseases and the risk of developing salivary stones: a case control study. Oral Surg Oral Med Oral Pathol Oral Radiol, 2015. 119(5): p.539-43.
11. Burke CJ, Thomas RH, Howlett D. Imaging the major salivary glands. Br J Oral Maxillofac Surg 2011;49:2619.

12. Rinast E, Gmelin E, Hollands-Thorn B. Digital subtraction sialography, conventional sialography, highresolution ultrasonography and computed tomography in the diagnosis of salivary gland diseases. Eur J Radiol 1989;9:224-30.

13. Yajima A, Otonari-Yamamoto M, Sano T, Hayakawa Y, Otonari T, Tanabe K, et al. Cone-beam CT (CB Throne) applied to dentomaxillofacial region. Bull Tokyo Dent Coll 2006;47:133-41.

14. Drage NA, Brown JE. Cone beam computed sialography of sialoliths. Dentomaxillofac Radiol 2009;38:301-5.

15. Zakaria MA. Giant calculi of the submandibular salivary gland. Br J Oral Surg 1981;19:230-2.

16. 15 Akin I, Esmer N. A submandibular sialolith of unusual size: a case report. J Otolaryngol 1991;20:123-5.

17. Mustard TA. Calculus of unusual size in Wharton's duct. Br Dent J 1945;79:129.

18. Rust TA, Messerly CD. Oddities of salivary calculi. Oral Surg Oral Med Oral Pathol 1969;28:862-5.

19. Brusati R, Fiamminghi L. Large calculus of the submandibular gland: report of case. J Oral Surg 1973;31:710-1. 